\title{
SAUL KRIPKE: A CRÍTICA À TEORIA DESCRITIVISTA DOS NOMES PRÓPRIOS
}

\author{
Daniel Artur Emídio Branco ${ }^{1}$
}

\section{Resumo:}

Este artigo almeja estudar a crítica do filósofo Saul Kripke à Teoria Descritivista dos Nomes Próprios. O artigo contém quatro seções. A primeira seção investigará a relação entre a Teoria Descritivista dos Nomes Próprios e a ideia de designadores rígidos. A segunda seção tratará do diálogo direto e indireto entre diferentes autores e a crítica kripkeana. A terceira seção estudará a lógica e a semântica de Kripke. A quarta e última seção investigará a interpretação kripkeana de Wittgenstein, assim como a relação entre a teoria dos nomes e o Paradoxo Cético.

Palavras-Chave: Descritivismo. Designador. Nome. Rigidez. Semântica.

\section{SAUL KRIPKE: THE CRITIQUE OF THE DESCRIPTIVIST THEORY OF PROPER NAMES}

\begin{abstract}
:
This paper studies a critique of the philosopher Saul Kripke to the Descriptive Theory of Names. The paper haver four sections. The first section investigates the relationship between the Descriptive Theory of Names and the idea of rigid designators. The second section deals with direct and indirect dialogue between different authors and Kripkean critique. Thr third section studies Kripke's logic and semantics. The fourth and final section investigates Kripkean interpretation of Wittgenstein, as well as the relationship between the theory of names and the Skeptical Paradox.
\end{abstract}

Keywords: Descriptivism. Designator. Name. Rigidity. Semantics.

\section{Introdução}

Este artigo tem a intenção de investigar a crítica de Kripke à Teoria Descrivista dos Nomes Próprios. Para tanto, serão elaboradas quatro seções. A primeira, falará dos primeiros autores a defenderem essa teoria, relacionando-os à crítica de Kripke. Ainda investigará a noção kripkeana de “designadores rígidos”. A segunda seção estudará autores que direta ou indiretamente dialogam com Kripke. A terceira seção falará dos aspectos centrais da lógica e da semântica kripkeanas. A quarta e última seção investigará a interpretação que Kripke empreende de Wittgenstein, bem como a relação entre o Paradoxo do Cético e os nomes.

1 Pós-doutorando em Filosofia pela Universidade Federal do Ceará (UFC), Doutor em Filosofia pela Universidade Federal do Ceará (UFC), Mestre em Filosofia pela Universidade Federal do Ceará (UFC), Licenciado em Filosofia pela Universidade Estadual do Ceará (UECE), Bacharel em Filosofia pela Universidade Estadual do Ceará (UECE), Bacharel em Teologia pela Faculdade de Teologia Integrada (FATIN) e diplomado em Especialização em História do Brasil pelo Instituto Superior de Teologia Aplicada (INTA). E-mail: darturemidio-26@hotmail.com. 


\section{A Teoria Descritivista dos Nomes Próprios e os Designadores Rígidos}

Saul Kripke, filósofo americano, desafia a Teoria Descritivista dos Nomes Próprios, que de um modo ou de outro também inclui os primeiros proponentes da filosofia analítica, como Gottlob Frege, Bertrand Russell e o Primeiro Wittgenstein, além de autores como John Searle. A Teoria Descritivista dos Nomes Próprios defende que os nomes próprios são descritivos ou sinônimos de descrição (mais precisamente de descrições definidas). A referência de um nome, portanto, não estaria fora dele (separada), mas seria expressada pelo nome mesmo. Mesmo que seja considerada um conjunto de descrições (as descrições cluster), ela, a referência, estaria associada a um nome próprio. Kripke rejeita todas as expressões dessa visão. Ele propõe a ideia de designador rígido embora não se queira dizer com isso que ele inventou este conceito. De acordo com Cícero Barroso, a tese dos designadores rígidos "é apresentada já no prefácio de Naming and Necessity e assevera que quando um nome próprio ' $n$ ' refere um objeto $b$ no mundo atual, 'n' refere bem todos os mundos possiveis em que b existe" (BARROSO, 2012, p. 110). Como dito, na ideia de designador rígido Kripke o nome indicaria um mesmo objeto em todos os mundos possíveis - - mesmo que isso possa ser interpretado como um argumento mais semântico que metafísico. Isso se difere da teoria contrafatual de David Lewis-Robert Stalnecker. Lewis, por exemplo, defende que todos os mundos possíveis existem - realismo modal - e que para a sentenças como "eu não chutei e o nosso time perdeu" o contrafatual "se eu tivesse chutado, o nosso time teria vencido" é verdadeiro porque em um mundo possível eu fiz o chute e o nosso time ganhou.

Enquanto Russell pudesse pensar que as sentenças "Bismarck foi um político cruel" e "o primeiro chanceler do Império Germânico foi cruel” denotassem a mesma coisa, Kripke nega (pelo menos nega que sempre denotem a mesma coisa). Ora, em algum mundo possível "o primeiro chanceler do Império Germânico" pode não ser Bismarck. Outros exemplos dados por Kripke para tratar da designação rígida são os dos termos água e H2O (KRIPKE, 2001, p. 128), a relação entre o nome Richard Nixon e o termo "o homem que venceu a eleição de 1968" (IBIDEM, 2001, p. 40) e a relação entre os nomes Hesperus e Phosphorus (IBIDEM, 2001, pp.20-21). Todos estão na obra Naming and Necessity. No primeiro exemplo, Kripke propõe que se a condição da água ser água é ela ser também $\mathrm{H} 2 \mathrm{O}$, então em todos os mundos possíveis água e $\mathrm{H} 2 \mathrm{O}$ se equivalem. Aqui tem-se um caso em que termos para elementos naturais são tratados como designadores

\begin{tabular}{|l|c|c|c|c|}
\hline Qevista Dialectus & Ano 9 & n. 19 & Agosto-Dezembro 2020 & p. $305-317$ \\
\hline
\end{tabular}


rígidos. No segundo exemplo, o mesmo não acontece. "Richard Nixon" não equivale a “o homem que venceu a eleição de 1968” em qualquer mundo possível. Não há uma identidade necessária entre ambos. O terceiro exemplo é bastante curioso. Hesperus e Phosphorus designam o mesmo planeta: vênus. Entretanto, anteriormente pensava-se que Hesperus, a Estrela Vespertina, tinha um referente diferente de Phosphorus, a Estrela Matutina. Neste caso, não se chegou a ideia de que ambos têm o mesmo referente a priori, mas, sim, a posteriori.

Tratando da ideia de necessidade a posteriori em Kripke, Soames explica uma importante distinção kripkeana a ela associada: a distinção entre mundos concebivelmente possíveis e mundos realmente possíveis. Soames afirma: “[Para Kripke], Estados-do-mundo metafisicamente possíveis são formas maximamente completas de como o universo concreto real poderia ter sido [...] Estados- -do-mundo epistemicamente possíveis são formas maximamente completas em que se poderia conceber o universo" (SOAMES, 2013, p.163).

Em Reference and Existence, Kripke discorre sobre a relação entre Clark Kent e Super-homem, como segue:

O Super-homem que se disfarça como Clark Kent pode ser verdadeiro e o Clark Kent que se disfarça de Super-homem falso. O Super-homem é sua verdadeira identidade: ele está apenas se disfarçando de um repórter comum e educado. Então, Super-homem "aparece como" Clark Kent em um sentido em que Clark Kent não "aparece" como Super-homem: isso é verdade. Mas isso não mostra que Clark Kent não é o Super-Homem: apenas mostra que "a aparece como b" é uma espécie de relação intensiva e opaca [...] que uma entidade pode ter consigo mesma (KRIPKE, 2013, p. 92).

Grosso modo, Kripke propõe em A Puzzle About Belief um enigma no qual Pierre, um francês que nunca foi à Inglaterra e que não sabe uma só palavra em inglês, acredita que "Londres est jolie". Com essa sentença ele quer dizer "Londres é bonita (London is pretty)". Porém, por vicissitudes da vida, Pierre vai morar numa parte não atrativa de Londres. Lá os moradores usam (também para este lado da cidade) a palavra “Londres (London)". Após essa experiência negativa, Pierre não está mais inclinado a assentir com a sentença "Londres é bonita (London is pretty)", pois para ele agora "Londres não é bonita (London is not pretty)". Entretanto, essa mudança não desfaz o fato de que para ele "Londres est Jolie". O que ele chama de "Londres (London)" é apenas uma parte feia da cidade, e não aquilo que Pierre entende por "Londres" na sentença “Londres est Jolie" (IBIDEM, 2011, pp. 143-144).

\begin{tabular}{|l|c|c|c|c|}
\hline Qevista Dialectus & Ano 9 & n. 19 & Agosto - Dezembro 2020 & p. 305-317 \\
\hline
\end{tabular}


Associado à essa ilustração da descoberta a posteriori em Kripke (presente nos casos de Hesperus e Phosphorus, London is not pretty etc.) está o seu conceito de Teoria Causal dos Nomes. Para ele, os nomes são dados como um batismo e são designados mediante uma cadeia causal, como bem se explica em Naming and Necessity. No seu exemplo explicativo dessa cadeia causal, Kripke propõe que se pense no nascimento de um bebê. Os pais do bebê o batizam com um determinado nome (pense-se em um nome próprio específico: João, Maria etc.). Esse é o chamado batismo inicial. A família então passa a relacionar o nome específico à criança. Porque nem todos conseguem fazer isso, por serem desconhecidos da família e não conhecerem a criança, Kripke busca demonstrar que a designação se dá mediante uma cadeia causal que passa pelos observadores originais, pais, família, pelo bebê etc. Agora o batismo inicial foi transmitido por uma cadeia causal. Alguém no fim dessa cadeia, embora não tenha estado na ocasião em que nome foi escolhido para o bebê, pode aprender com um observador original e, assim, passar a usar o nome específico da criança com a mesma intenção que os pais dela e os seus familiares (IBIDEM, 2001, pp. 91-92). Um caso desses, supondo que o nome da criança (se for brasileira) seja João, Maria etc., é possível. Kripke, porém, sustenta que o nomear um pet aardvark de Napoleão dificultaria a transmissão do batismo inicial pela corrente causal, pois a associação entre "Napoleão" (nome de um líder francês famoso), "pet" (animal), “aardvark", etc., tornaria mais complexo o estabelecimento dessa cadeia causal entre os familiares.

\section{Autores que dialogam, direta ou indiretamente, com a perspectiva de Kripke}

Voltando ao exemplo da relação natural entre água e $\mathrm{H} 2 \mathrm{O}$, faz-se pertinente apresentar os experimentos propostos por Hillary Putnam e por Donald Davidson, que também tratam, ou dessa relação, ou de uma ideia semelhante. O experimento de Putnam é o seguinte: suponha-se que em algum do universo exista um planeta igual em tudo à Terra. Suponha-se também que exista nesse planeta um líquido igual à água, com exceção dos componentes químicos, que, ao invés de serem H2O, são chamados de XYZ. Em português, tanto quem está na Terra como na "Terra Gêmea" olham para o líquido e o chamam de água, embora um seja $\mathrm{H} 2 \mathrm{O}$ e o outro, XYZ. Tem-se, pois, o fato de que, do ponto de vista externo, a experiência de ambos é idêntica. Entretanto, como fica a questão da intencionalidade? Se XYZ e H2O não são a mesma coisa como se pode afirmar que

\begin{tabular}{|l|l|l|l|l|}
\hline Qevista Dialectus & Ano 9 & n. 19 & Agosto - Dezembro 2020 & p. $305-317$ \\
\hline
\end{tabular}


há um mesmo referente e a mesma intencionalidade aí? Se XYZ e H2O são iguais apenas externamente, mas não designam estrutural e internamente a mesma coisa, a intencionalidade presente em que pensa "XYZ" não podem ser a mesma daquela existente em que pensa "H2O". Não é isso que se deve inferir dessa questão? Por isso, esse experimento de Putnam ficou conhecido por expressar um conceito chamado de externalismo semântico.

O experimento de Donald Davidson consiste no seguinte: suponha-se que um homem, Davidson, caminha por um pântano e é atingido e morto por um relâmpago, enquanto, simultaneamente, outro raio, próximo dali, ordena acidentalmente um conjunto de moléculas de um modo tal que elas formam um ser que "toma o lugar" de Davidson, isto é, que tem a mesma forma que Davidson tinha, incluindo a mesma estrutura cerebral. Esse ser, ao sair do pântano, irá tomar todas as posições acadêmicas, fraternais e familiares que Davidson possuía. Todavia esse ser é "o homem do pântano", e não Davidson. Ele não teria experiência de nada do que iria conhecer ao sair do pântano. Poderiam os enunciados do "homem do pântano" se referir a coisas particulares? Mesmo que ele fosse idêntico a Davidson, as referências para os seus enunciados seriam as mesmas de Davidson? A resposta negativa é a mais prudente.

O experimento mental de Davidson, assim como o do Hillary Putnam, tem sido interpretado como que invocando o conceito de externalismo semântico (outro pensador associado a uma ideia externalista é o filósofo anti-individualista Tyler Burge). Assim como esses dois, Kripke foi associado ao externalismo semântico, pelo menos o seu exemplo da identidade entre água e $\mathrm{H} 2 \mathrm{O}$ é visto como aproximado do exemplo de Davidson e da ideia de Putnam. Entretanto, diferentemente dos experimentos de Putnam e de Davidson, quando Kripke sugere que "se" a "condição" para água ser água é que ela é H2O ele está dando um exemplo de identidade absoluta entre nome e referência. Isso não é uma questão de puro externalismo. A rigidez do nome "água" para designar $\mathrm{H} 2 \mathrm{O}$ envolve os aspectos natural e real desses componentes, não apenas equivalências semânticas externas (água teria que ser H2O "estrutural" e "internamente", não apenas exteriormente). O conceito de designador rígido de Kripke, assim, vai além da ideia expressada pelos experimentos de Putnam e Davidson.

Quanto à crítica kripkeana à teoria de identidade tipo-tipo de Place e Smart, Domingos Faria elucida:

\begin{tabular}{|l|c|c|c|c|}
\hline Q & Anista & n. 19 & Agosto - Dezembro 2020 & p. 305 - 317 \\
\hline
\end{tabular}




\begin{abstract}
Os teóricos da identidade tipo-tipo, como Place ou Smart, quando afirmam que "a consciência é um processo que ocorre no cérebro" ou que "as sensações são processos cerebrais" estão a sustentar a seguinte tese: certos tipos de estados mentais são idênticos a certos tipos de estados cerebrais [...] ao contrário daquilo que os teóricos da identidade tipo-tipo alegam, Kripke defende que se há identidade, então a identidade é necessária [...]se é contingente que a dor seja a estimulação das fibras C (como supõem Place e Smart), então temos de admitir que não há qualquer identidade. Deste modo, a teoria da identidade tipo-tipo não seria uma boa resposta ao problema mente-corpo (FARIA, 2014, pp.112-113).
\end{abstract}

Oportuna também é a lembrança da relação de Kripke com o pensamento de Robert Brandom, para quem "a neve é branca" pode funcionar anaforicamente, isto é, quando um operador de verdade (WANDERER, 2014, p. 180) funciona como o nome da sentença (antecedente) do qual se infere a seguinte (BRANDOM, 1994, p. 606-607), ou ainda, quando "'a neve é branca' é verdadeiro" não diz respeito a uma correspondência entre o objeto linguístico e um objeto não linguístico, mas, sim, a um tornar explícito um compromisso (anafórico) com o iniciador anafórico "a neve é branca" (TURBANTI, 2017, p. 91. Sob a influência de Richard Rorty e David Lewis, Brandom desenvolveu as ideias de holismo semântico, de negação determinada e de salto do entendimento à razão (BAVARESCO, 2012, pp. 11-16). Ele faz uma espécie de intersecção entre o pensamento hegeliano e a Filosofia Analítica, destacando também o inferencialismo e o pragmatismo, criticando o rigor eu-nós, eu-tu, dos scorekeeping deônticos. Na filosofia brandomiana há "três conceitos metodológicos: (i) o movimento inferencial do conceito; (ii) a dialética entre o todo e as partes; e (iii) a negação determinada e a contradição como o núcleo do sistema hegeliano" (IBIDEM, 2012, p. 16). No primeiro, "o Ser do conceito encontra [...] o jogo prático em que há a passagem entre atores sociais” (IBIDEM, 2012, p.17). No segundo, ("a Essência do conceito realiza-se na mediação do processo de reconhecimento" (IBIDEM, 2012, p.17). No terceiro, "o Conceito em si realiza, no desenvolvimento de relações inferenciais nos conteúdos assertivos expressos por sentenças nas práticas de estatutos normativos” (IBIDEM, 2012, p.17).

Em Brandom, "conhecimento absoluto é o movimento da consciência no qual as partes que são o sujeito e o objeto suprassumem sua contradição como um jogo do todo e das partes [...] a ideia absoluta é o desenvolvimento da ideia lógica no todo dos conceitos [...] é a unidade do Ser e da Essência (Lógica Objetiva) e do Conceito (Lógica Subjetiva)" (IBIDEM, 2012, pp. 17-18), então “(iii) o espírito absoluto são os três silogismos lógicos entre três figuras diferentes: (1) Lógica - Natureza - Espírito; (2) Natureza - Espírito Lógica; e (3) Espírito - Logica - Natureza" (IBIDEM, 2012, p. 18). A "suprassunção

\begin{tabular}{|c|c|c|c|c|}
\hline Govista Dialectus & Ano 9 & n. 19 & Agosto - Dezembro 2020 & p. $305-317$ \\
\hline
\end{tabular}


(Aufhebung) [...] envolve a sequência dialética: (1) afirmação; (2) negação; e (3) negação da negação = afirmação de algo novo" (IBIDEM, 2012, p. 19).

Sobre importância de Kripke, Brandom pontua "o desenvolvimento seminal de Kripke sobre a semântica dos mundos possíveis para o conjunto das lógicas modais de C. I. Lewis, o emprego desse aparato para fornecer uma semântica intensional para uma série de expressões não-lógicas, e as sequelas do tratamento de Kripke aos nomes próprios, em Naming and Necessity" (BRANDOM, 2011, p. 85). E ainda: "resta-nos ainda realizar uma reconciliação e síntese entre a abordagem de modalidade feita por Kripke-Kaplan-Stalnaker-Lewis (David) e a abordagem feita por Kant-Hegel-Sellars" (IBIDEM, 2011, p. 86). Apesar das diferenças entre eles, Brandom reconhece que a importância de Kripke para os seus insights "hegelianos" na Filosofia Analítica - vale lembrar que o idealismo de F. A. Bradley chegou a influenciar Russell, mas posteriormente foi criticado por ele. Decerto, a negação kripkeana da identidade entre os nomes próprios e a referência, tal como queriam Frege e Russell, é um fator real para tais novos insights na Filosofia anglo-saxã, ainda que não sejam propriamente "hegelianos".

O Princípio de Russell, de Gareth Evans, segundo o qual uma pessoa não pode estar pensando sobre um objeto a menos que ele saiba que está pensando sobre o objeto (e isso tem que ser de um modo não trivial) também estão, de certa forma, relacionadas à crítica de Kripke à Teoria Descritivista dos Nomes Próprios. Já quanto à Teoria Deflacionária da Verdade, interessante é o debate gerado em torno dessa teoria. Strawson, com Ramsay - que também é conhecido pela teoria da redundância-, defende a teoria performativa da verdade. Brandom também tem sido associado ao prosentencialismo.

Também para Strawson (a relação entre os sortais e universais) a metafísica descritivista busca descrever a estrutura do pensamento, enquanto a metafísica revisionista busca revisar ideias inadequadas. É possível ter-se significado sem referência. Uma locução pode ter significado e, ao mesmo tempo, não se referir a nada, como acontece nas fábulas (ALMEIDA, 2011, p.3). Já Keith Donnellan faz distinção entre descrições definidas e descrições atributivas. Um trabalho mais profundo sobre a relação das ideias desses autores e a crítica empreendida por Kripke, bem como com a noção de designadores rígidos, faz-se importante.

Em A Puzzle About Belief, Kripke critica a posição não descritivista de Stuart Mill a respeito dos nomes próprios. Mill, diferentemente de Frege, não relacionava a conotação aos nomes próprios, mas apenas denotação. Semelhante a crítica de Frege a

\begin{tabular}{|l|c|c|c|c|}
\hline Qevista Dialectus & Ano 9 & n. 19 & Agosto-Dezembro 2020 & p. 305-317 \\
\hline
\end{tabular}


Mill ("Cícero é Cícero", "Cícero é Túlio", "Frege acredita que Cícero é Túlio", Frege acredita que Cícero é Túlio", "Frege não acredita que Cícero é Túlio"), Kripke não reconhece a redução do nome à denotação: "segundo Mill, um nome próprio é, por assim dizer, simplesmente um nome. Refere-se simplesmente ao seu portador e não possui outra função linguística” (KRIPKE, 2011, p. 126). Ele acrescenta:

\begin{abstract}
Se uma estrita visão milliana estiver correta, e a função linguística de um nome próprio estiver completamente esgotada pelo fato de nomear seu portador, parece que nomes próprios da mesma coisa são intercambiáveis em todos os lugares, não apenas salva veritate, mas até salva significatione: a proposição expressa por uma sentença deve permanecer a mesma, independentemente do nome do objeto que ela usa. É claro que isso não será verdade se os nomes forem 'mencionados' em vez de 'usados': "'Cicero' tem seis letras" difere de "'Túlio' tem seis letras" [...] Se Mill está completamente certo, não apenas "Cícero era preguiçoso" deveria ter o mesmo valor de verdade de "Túlio era preguiçoso", mas as duas frases deveriam expressar a mesma proposição, ter o mesmo conteúdo. Da mesma forma, "Cícero admirava Túlio", "Túlio admirava Cícero", "Cícero admirava Cícero" e "Túlio admirava Túlio", deveriam ser quatro maneiras de dizer a mesma coisa (IBIDEM, 2011, p.127).
\end{abstract}

\title{
3. Lógica e semântica kripkeanas
}

A definição da semântica de Kripke para a lógica proposicional é a seguinte: “Assuma-se que a fórmula $F$ tenha sido construida com fórmulas 'atômicas' B1, B2, ..., Bn usando apenas conectivos proposicionais. Em vez de considerarmos valores de verdade $F$ para todas as possíveis tuplas de valores de verdade de B1, B2, ..., Bn, consideremos o comportamento de F em todos os cenários possíveis de Kripke" (DETLOVS, 2012, p. 160). Pois bem, “cada cenário s é um triplo $(b, \leq t)$ dos seguintes objetos. Primeiro, b é um conjunto finito de objetos chamados nós (ou estados) [...] Daí o segundo membro sé uma relação de ordenação parcial entre os nós, isto é, para todos $x, y, z \in b: x \leq y \rightarrow(y \leq z \rightarrow x \leq z)$ (transitividade)" (IBIDEM, 2012, pp. 160-161). Já o “terceiro membro t do triplo é uma função (t significa 'verdadeiro'). Se associa com cada nó $x$ um conjunto 'crescente' $t(x)$ de fórmulas 'atômicas', isto é, um subconjunto de $\{B 1$ , B2 , ..., Bn \} de modo que, para todos os $x, y \in b: x \leq y \rightarrow t(x) \subseteq t$ (y)" (IBIDEM, 2012, p.161).

Em A Completeness Theorem in Modal Logic, Kripke buscou "afirmar e provar um teorema de completude para o sistema S5 de [1], complementado por quantificadores de primeira ordem e o sinal de igualdade" (KRIPKE, 1959, p. 1). Esses

\begin{tabular}{|l|l|l|l|l|}
\hline Qevista Dialectus & Ano 9 & n. 19 & Agosto - Dezembro 2020 & p. $305-317$ \\
\hline
\end{tabular}


sistemas são complementados "pelos seguintes esquemas de axiomas e regras de inferência

$$
\begin{aligned}
& \text { A1: } \square A \supset A \\
& \text { A2: } \backsim A \supset \backsim \square \sim \square A \\
& \text { A3: ם(A } \supset B) . \supset . \square A \supset \square B \\
& \text { R1. Se } \vdash A \text { e } \vdash A \supset B, \text { então } \vdash B \\
& \text { R2. Se } \vdash A \text {, então } \vdash \square A "(\text { KRIPKE, 1959, p.1). }
\end{aligned}
$$

Sobre o modelo de lógica intuicionista de Kripke, Burgess afirma: "esse modelo $\mathrm{M}=(\mathrm{X}, \mathrm{a}, \mathrm{R}, \mathrm{V})$ consiste em um conjunto $\mathrm{X}$ de índices, um índice distinto a, uma relação binária reflexiva e transitiva $\mathrm{R}$ e uma avaliação $\mathrm{V}$ com a propriedade especial chamada hereditária, o que significa que se A é um átomo e se $\mathrm{V}(\mathrm{x})(\mathrm{A})=\mathrm{T}$ e se xRy, então V (y) (A) = T” (BERGER, 2011, s/p). Para a definição de verdade em Kripke, Burgess apresenta o seguinte modelo:

“(0) Para atômico A, A é verdadeiro se $\quad V(x)(A)=\mathrm{T}$

em $x$ em $M$

(1) $\neg A$ é verdadeiro $x$ em $M$

(2) $\quad A \& B$ é verdadeiro em $x$ em $M \quad$ se se

se

se para qualquer y com $x R y, A$ não é verdadeiro em $y$ em $M$ $A$ é verdadeiro em x em $M$ ou $B$ é verdadeiro $x$ em $M$ $A$ é verdadeiro em $x$ em $M$ ou $B$ é verdadeiro em $x$ em $M$ para qualquer $y \operatorname{com} x R y$, se $A$ é verdadeiro em $y$ e, $M$, então B é verdadeiro em y em M" (IBIDEM, 2011, s/p).

\section{O Wittgenstein kripkeano ou o kripkenstein: o Paradoxo do Cético}

Outra faceta importante do pensamento kripkeano é a sua interpretação do Segundo Wittgenstein. Kripke propõe que no livro Investigações Filosóficas está contido um Paradoxo Cético: "Wittgenstein inventou uma nova forma de ceticismo" (KRIPKE,

\begin{tabular}{|l|l|l|l|l|}
\hline Qenista Dialectus & Ano 9 & n. 19 & Agosto - Dezembro 2020 & p. $305-317$ \\
\hline
\end{tabular}


1982, p.60). Não é que Wittgenstein tenha defendido uma "teoria" sobre o ceticismo, mas que o seu escrito conduz a essa interpretação. Assim, a leitura que o autor americano faz de Investigações Filosóficas é ousada e peculiar. A singularidade da interpretação kripkeana de Wittgenstein ganhou a alcunha de "kripkenstein". Essa interpretação, entretanto, mostra-se plausível, pois de fato o "paradoxo wittgensteiniano" e o estudo da linguagem privada empreendido por Wittgenstein parecem levar a uma espécie de ceticismo.

No entender kripkeano, o "paradoxo wittgensteiniano” já ocorre no parágrafo 202 de Investigações Filosóficas. É que o argumento da linguagem privada está presente nesse parágrafo, antes do parágrafo 243 , e ele deve nortear a interpretações dos parágrafos seguintes que tratam do mesmo argumento da linguagem privada:

\begin{abstract}
Na minha opinião, o verdadeiro "argumento da linguagem privada" pode ser encontrado nas seções anteriores ao §243. De fato, no §202 a conclusão já está declarada explicitamente: "Portanto, não é possível obedecer a uma regra 'em particular': caso contrário, pensar que alguém estava obedecendo a uma regra seria a mesma coisa que obedecê-la." Eu não acho que Wittgenstein aqui pensou em si mesmo como antecipando uma discussão que ele iria empreender em maiores detalhes mais tarde. Pelo contrário, as considerações cruciais estão todas contidas na discussão que antecede a conclusão declarada no §202. As seções a seguir ao §243 devem ser lidas à luz da discussão anterior; por mais difíceis que sejam, elas são menos propensas a serem entendidas se forem lidas isoladamente (IBIDEM, 1982, p. 3).
\end{abstract}

Kripke fala então sobre a questão das regras aplicadas à tautologia matemática e ao sinal de "+" e ao conceito de "mais":

Suponhamos, por exemplo, que ' $68+57$ 'seja um cálculo que eu nunca fiz antes [...] Realizo o cálculo, obtendo, é claro, a resposta '125'. Estou confiante, talvez depois de verificar meu trabalho, que '125' seja a resposta correta. Está correto tanto no sentido aritmético que 125 é a soma de 68 e 57, quanto no sentido metalinguístico que 'mais' [...] denotava uma função que, quando aplicada aos números que chamei '68' e '57', produz o valor 125. Agora, suponha que eu encontre um cético bizarro. Esse cético questiona minha certeza sobre minha resposta, no que acabei de chamar de sentido "metalinguístico". Talvez, ele sugere $[\ldots]$ a resposta que pretendia para ' $68+57$ 'deveria ter sido' 5 '! (IBIDEM, 1982, p. 8).

Ele continua:

talvez no passado eu tenha usado 'mais' e 't' para denotar uma função que chamarei de 'quus' [...] [que defino] por:

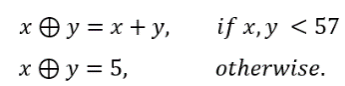

\begin{tabular}{|l|l|l|l|l|}
\hline Qevista Dialectus & Ano 9 & n. 19 & Agosto - Dezembro 2020 & p. $305-317$ \\
\hline
\end{tabular}


Quem pode dizer que essa não é a função que anteriormente se entende por '+'? [...] o problema não é "Como eu sei que 68 mais 57 é 125?", o que deve ser respondido com um cálculo aritmético, mas sim "Como eu sei que '68 mais 57 ', como eu quis dizer 'mais' no passado, deve denotar 125? " Se a palavra 'mais', como a usei no passado, denotava a função quus, não a função mais [...] então minha intenção passada era tal que, pedido o valor de '68 mais 57', eu deveria responder '5' (IBIDEM, 1982, pp. 8-9-12).

A interpretação kripkeana de Wittgenstein também funciona como crítica a Teoria Descritivista dos Nomes Próprios. Não há descritivismo no Paradoxo do Cético. Mas alguns discordam dessa interpretação kripkeana. Entre eles, está John Mcdowell, que, com o seu realismo de propriedade secundário influenciado pelo conceito de "mito do dado", de Sellars, e por Hegel, critica a teorização de Kripke sobre o ceticismo em Wittgenstein, afirmando que ele conflita com a hostilidade wittgensteiniana para com a teorização filosófica (THORNTHON, 2014, p. 36).

\section{Conclusão}

Este artigo se conclui pela observação de que a crítica de Kripke à Teoria dos Nomes Próprios é pertinente. A noção de designadores rígidos ainda precisa ser melhor desenvolvida e, com ela, a clareza semântica. É plausível a leitura que Kripke faz do Segundo Wittgenstein.

Sem dúvidas, a considerável soma de autores contemporâneos que dialogam direta ou indiretamente com o pensamento kripkeano não é um acidente de percurso, mas fruto de um trabalho atual e relevante do autor americano.

\section{Referências Bibliográficas}

ALMEIDA, Jones. O conceito de referência na obra de P.F. Strawson e S. Kripke e a teoria contratual da referência na semiótica de Umberto Eco. XII Congresso Internacional da ABRALIC Centro, Centros - Ética, Estética, Curitiba: UFPR, 2011.

BARROSO, Cícero. A crítica de Kripke às teorias descritivistas de nomeação. Recife: Perspectiva Filosófica, v. II, n. 38, ago./dez. 2012.

BAVARESCO, Agemir; CARMO, Juliano do. A Pragmática Normativa de Robert Brandom. Porto Alegre: IX SAPPGFIL PUCRS ISSN 2237-2539, 2012.

BERGER, Alan. Saul Kripke - Kripke Models. UK: Cambridge University Press, UK, 2011.

\begin{tabular}{|l|c|c|c|c|}
\hline Qevista Dialectus & Ano 9 & n. 19 & Agosto-Dezembro 2020 & p. 305-317 \\
\hline
\end{tabular}


BRANDOM, Robert. Hegel e Filosofia Analítica. Porto Alegre: Veritas, v. 56, n. 1, jan./abr., 2011, p. 78-94.

, Robert. Making it Explicit. Reasoning, Representing, and Discursive

Commitment. USA: Harvard University Press, 1994.

CARVALHO, Marcelo; BRAIDA, Celso; SALLES, João; CONLIGLIO, Marcelo. Filosofia da Linguagem e da Lógica. São Paulo: Coleção XVI Encontro ANPOF, 2015. DETLOVS, Vilnis; PODNIEKS, Karlis. Introduction to Mathematical Logic -Hypertextbook for students: Sections 1, 2, 3 of this book represent an extended translation of the corresponding chapters of the book: V. Detlovs, Elements of Mathematical Logic. Riga: University of Latvia, Latvia, 2012.

DONNELLAN, Keith. Essays on Reference, Language and Mind. New York: Oxford University Press, 2012.

FARIA, Domingos. Será procedente o argumento de Kripke contra a teoria da identidade tipo-tipo? Revista Portuguesa de Filosofia Vol. 70, Fasc. 1, pp. 112-131, 2014.

KRIPKE, Saul. A Completeness Theorem in Modal Logic. Association for Symbolic Logic. The Journal of Symbolic Logic, Vol. 24, No. 1, 1959.

, Saul. Naming and Necessity. USA: Harvard University Press. 2001.

, Saul. Philosophical Troubles - Collected Papers - Volume 1. New York:

Oxford University Press, 2011.

Saul. Reference and Existence - The John Locke Lectures. New York: Oxford University Press, 2013.

Saul. Wittgenstein on Rules and Private Language: An Elementary Exposition. USA: Harvard University Press, 1982.

MCDOWELL, John. Mind, Value and Reality. USA: Harvard University Press, 1998.

NETO, Fernando; SANTOS, Jeferson. "Referência e Descrições Definidas" de Keith Donnellan: Introdução ao Texto e Tradução. Revista Ágora Filosófica, Vol. No.1, 2017.

REDDING, Paul. Analytic Philosophy and Return of the Hegelian Thought. UK: Cambridge University Press, 2007.

SOARES, Daniel. Strawson: Esquema Conceitual e Ciência: o Caso da Percepção. Kínesis, Vol. VII, n 13, 2015.

SOMAES, Scott. Kripke sobre a possibilidade epistêmica e metafísica: As duas rotas para o necessário a posteriori. Trad. br. Daniel Soares da Silva. sképsis, ano vi, n 9, 2013.

\begin{tabular}{|l|c|c|c|c|}
\hline Qevista Dialectus & Ano 9 & n. 19 & Agosto-Dezembro 2020 & p. 305-317 \\
\hline
\end{tabular}


THORNTHON, Tim. John Mcdowell. USA: Routledge, 2014.

TURBANTI, Giacomo. Robert Brandom's Normative Inferentialism. Philadelphia: John Benjamin's Publishing Company, 2017.

WANDERER, Jeremy. Robert Brandom. New York: Routledge Taylor and Francis Group, 2014.

\begin{tabular}{|l|l|l|l|l|}
\hline Qevista Dialectus & Ano 9 & n. 19 & Agosto - Dezembro 2020 & p. $305-317$ \\
\hline
\end{tabular}

